\title{
Pleuropulmonary Toxicity of Another Anti-Parkinson's Drug: Cabergoline
}

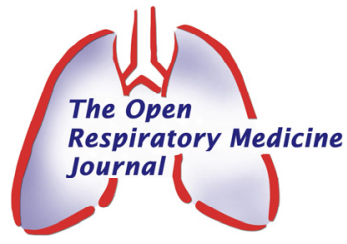

\author{
Yolanda Belmonte $^{1}$, Oriol de Fàbregues ${ }^{2}$, Marta Marti $^{3}$ \\ and Christian Domingo ${ }^{*}, 1,4$
}

\author{
${ }^{1}$ Pneumology Service, ${ }^{2}$ Neurology Service, ${ }^{3}$ Clinical Pharmacology Service, Corporació Sanitària Parc Taulí, Sabadell, \\ Barcelona, Spain \\ ${ }^{4}$ Autonomous University of Barcelona (UAB), Barcelona, Spain
}

\begin{abstract}
Many drugs may cause toxic injury to the lungs and the pleura. Cabergoline is an ergoline derivative which has been used in Spain for seven years to control symptoms of Parkinson's disease. We report a patient with dyspnea, bilateral pleural effusion and distal swelling. After a series of complementary tests (blood analysis, chest CT, echocardiogram, pleural tap, pleural biopsy), etiological screening ruled out infection, malignancy or inflammation. Given the patient's history of three years' treatment with cabergoline, the drug was considered a possible cause and was progressively withdrawn. The patient's clinical condition improved and radiological images were disease-free. Using Karch and Lasagna's classical criteria, we defined a relationship of "probable causality" between the drug and the adverse effects reported.
\end{abstract}

Keywords: Pleural effusion, pleural fibrosis, parenchymal lung opacity, cabergoline.

\section{INTRODUCTION}

Today, more than 350 drugs are known to produce pleuro-pulmonary damage [1]. The diagnosis of druginduced pulmonary disease is usually per exclusionem since in most cases there is no specific diagnostic test [1]. If disease is suspected, Karch and Lasagna's classical criteria are applied to try to establish causal relations [2]. We report a patient who developed pleuro-pulmonary pathology, mainly in the form of pleural effusion, after prolonged administration of cabergoline.

\section{CASE REPORT}

Sixty-five year-old male, ex-smoker with an accumulated dose of 40 packs-year and without any work-related history of interest. He had undergone surgery for colon cancer and was currently disease-free. He had Parkinson's disease of more than 10 years' evolution and had been receiving LDopa $(1600 \mathrm{mg} / \mathrm{d})$ combined with carbidopa $(250 \mathrm{mg} / \mathrm{d})$ and benserazide $(150 \mathrm{mg} / \mathrm{d})$ since the diagnosis, entacapone $(800 \mathrm{mg} / \mathrm{d})$ and cabergoline $4 \mathrm{mg} / \mathrm{d}$ (the latter added three years previously). He was referred to our unit for progressive dyspnea, swollen ankles and intolerance of the supine position for over a month. The only finding of interest in the physical examination was the presence of bilateral basal hypophonesis in the respiratory auscultation, regular heart rhythm without murmurs and pitting edemas in the lower half of both legs. Blood analysis: ESR 70, LDH 333, CRP 1.3, PSA, Reumatoid factor and anti-tissue antibodies

*Address correspondence to this author at the Pulmonary Service, Hospital de Sabadell (Corporacio Parc Taulí), Parc Taulí s/n, 08208 Sabadell, Barcelona, Spain; Tel: 34-93-723 10 10, Ext. 21 160; Fax: 34-93 71606 46; E-mail: cdomingo@tauli.cat were within reference values. Chest $\mathrm{x}$-ray: bilateral pleural effusion (Fig. 1). Electrocardiogram: sinus rhythm 75 per minute, without repolarization disturbance. Echocardiogram: alteration in ventricular relaxation with a left ventricle ejection fraction of $60 \%$ without valvulopathy and preserved global contractility. Initially, heart failure was considered; diuretic treatment was initiated, but only achieved a slight improvement in the distal swelling. Diagnostic pleural tap was compatible with a lymphocyte exudate with low ADA value (Table 1); cytological and microbiological studies (Ziehl-Neelsen stain and Lowenstein-Jensen culture) were negative. Pleural biopsy showed marked fibrosis and isolated areas of reactive mesothelial proliferation without evidence of malignancy. Chest CT showed bilateral pleural thickening and effusion affecting the underlying parenchyma (Fig. 2). Respiratory function testing: FVC 2.88L (73\%), FEV1 2.18L (77\%), FEV1/FVC $76 \%$ (bronchodilator test was nonsignificant), TLC 4.55L (73\%), RV 1.60L (76\%), DLCO $71 \%$, KCO $84 \%$. Arterial blood gas analysis on room air: $\mathrm{pH}$ 7.43, $\mathrm{PaO} 288.7 \mathrm{mmHg}, \mathrm{PaCO} 236.7 \mathrm{mmHg}$, bicarbonates $25.3 \mathrm{mEq} / \mathrm{L}$, Alveolo-arterial gradient $14 \mathrm{mmHg}, \mathrm{COHb}$ $0.4 \%$. Due to the poor clinical response to diuretic treatment and after ruling out other possible causes of the symptoms (infection, malignancy, systemic disease, renal failure) a pharmacological etiology was considered possible, and so carbegoline treatment was withdrawn (after agreeing on a new therapeutic approach with the neurology service). After two years of clinical and radiological follow-up, the patient had clinically improved, mild left pleural thickening persists (Fig. 3) and the pulmonary function testing shows a relative improvement of the restriction pattern (FVC 2.94L (75\%), FEV1 2.16L (76\%), FEV1/FVC 74\%, TLC 4.57L (73\%), RV 1.58L (73\%), DLCO 70\%, KCO 78\%). 


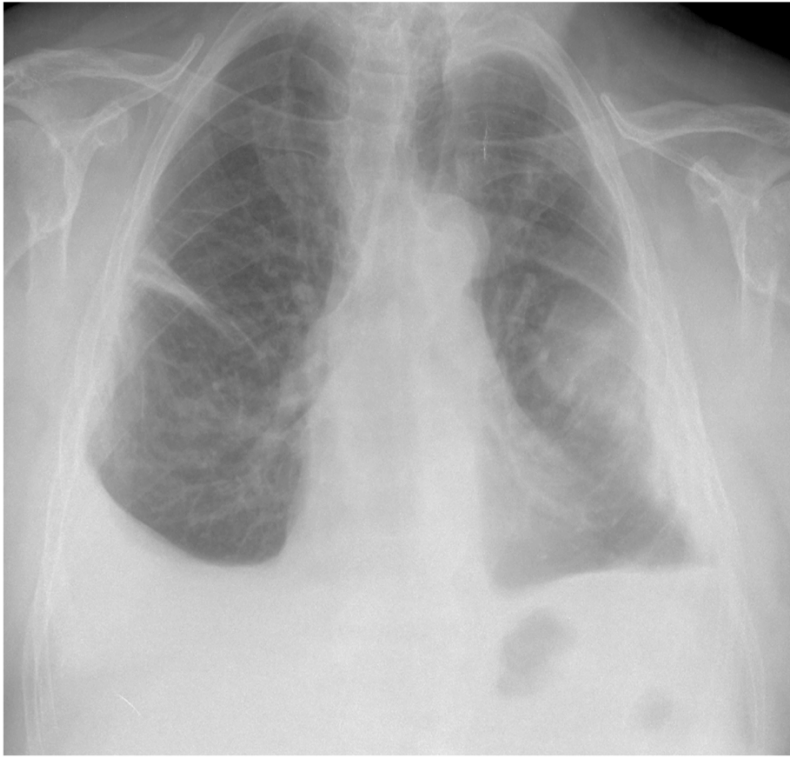

Fig. (1). Chest x-ray at the beginning of the study. Observe the pleural effusion affecting both hemithoraces.

(A)

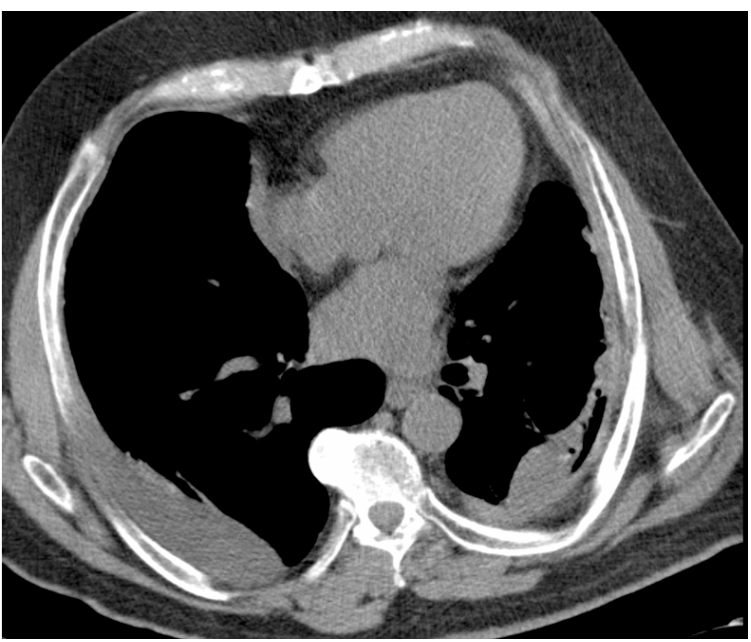

(B)

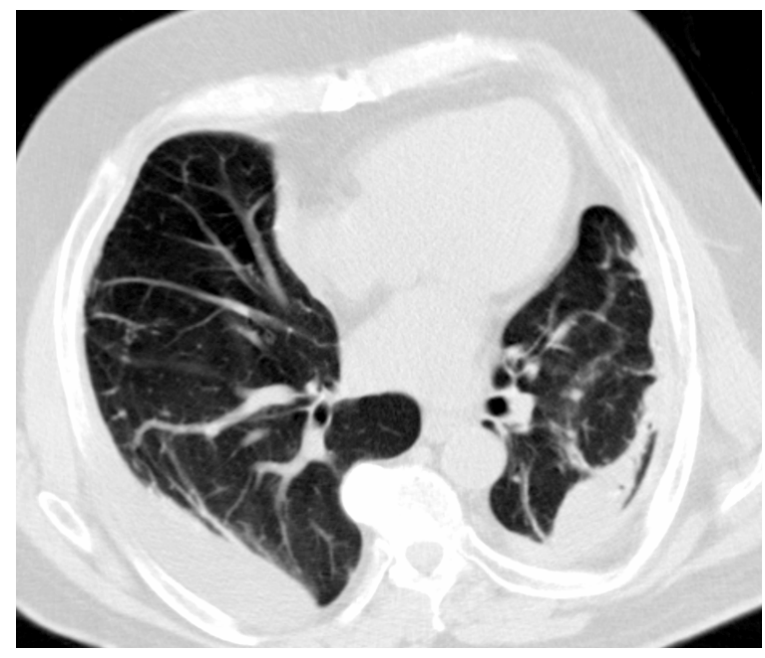

Fig. (2). (A: Mediastinal window and B: parenchymal window). CT Scan at the beginning. Observe the pleural effusion affecting both hemithoraces. Parenchymal lung opacities are also seen.
(A)

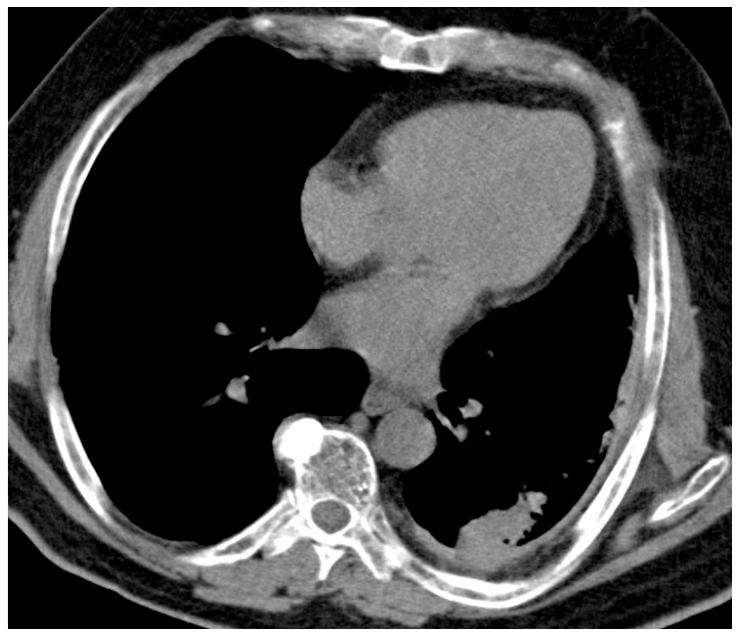

(B)

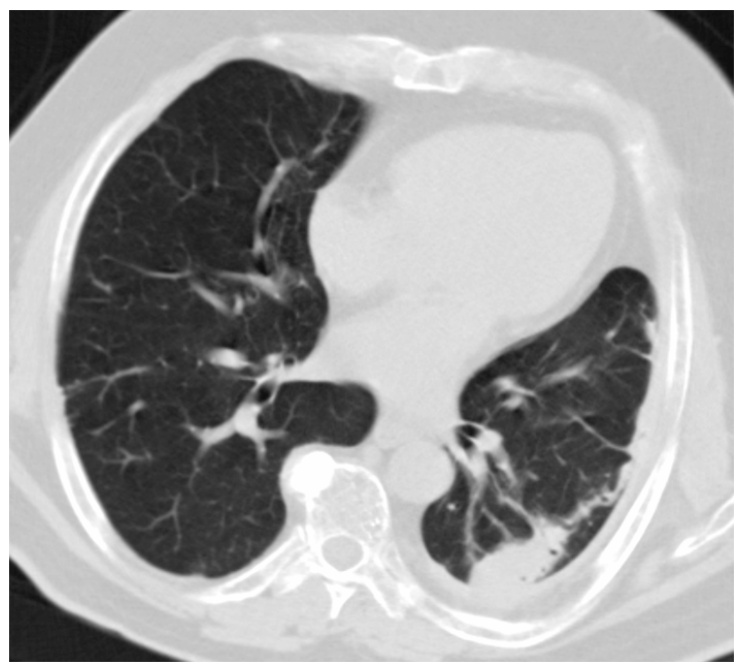

Fig. (3). (A: Mediastinal window and B: parenchymal window) CT scan at the end of follow-up. Observe the improvement in the pleuro-pulmonary abnormalities compared with the previous chest CT scan. The pleural effusion has disappeared, but pleural fibrosis remains to some extent.

Table 1. Characteristics of Patient's Pleural Fluid

$>$ Cellularity: 750 leukocytes per $\mathrm{mm}^{3}$,

$95 \%$ lymphocytes,

$5 \%$ neutrophils;

$>$ Ratio Proteins in Pleural Fluid/Blood (g/L): 51/ 79= 0.65

$>$ Ratio LDH in Pleural Fluid/Blood (U/L) 560/333 $=1.68$

$>$ ADA: $15.2 \mathrm{U} / \mathrm{L}$

\section{DISCUSSION}

Drug-induced pleural effusion is less frequent than druginduced parenchymal lung disease, though the two conditions may co-occur [1]. Some thirty substances are known to be possible causes of pleural effusion, among which the most frequent are: cardiovascular drugs (propranolol, amiodarone), ergoline derivatives (methysergide, bromocriptine), chemotherapy drugs (bleomycin, mitomycin, procarbazine, methotrexate, cyclophosphamide), 
Table 2. Review of the Literature

\begin{tabular}{|l|c|c|c|c|c|}
\hline \multicolumn{1}{|c|}{ Reference } & $\begin{array}{c}\text { Cabergoline } \\
\text { Dose }\end{array}$ & $\begin{array}{c}\text { Cabergoline's } \\
\text { Treatment Duration }\end{array}$ & $\begin{array}{c}\text { Length of Respiratory } \\
\text { Symptoms }\end{array}$ & $\begin{array}{c}\text { Treatment with } \\
\text { Oral Steroids }\end{array}$ \\
\hline \hline Villavicencio [2] & $1 \mathrm{mg} / \mathrm{day}$ & Four months & Three months & $\begin{array}{c}\text { Pleural efusión } \\
\text { Intersticial lung diasease } \\
\text { Pericardial thickening }\end{array}$ \\
\hline Bhatt MH [12] & $3 \mathrm{mg} / \mathrm{day}$ & $*$ & One month & Pleuropulmonary disease \\
\hline Frans E [13] & $*$ & Ten months & Three months & Pleuropulmonary disease & No \\
\hline Ling LH [14] & $10 \mathrm{mg} /$ day & Two years & $8-10$ weeks & $\begin{array}{c}\text { Pleuropulmonary inflammatory-fibrotic } \\
\text { syndrome }\end{array}$ & No \\
\hline Frank W [15] & $1 \mathrm{mg} / \mathrm{day}$ & Four months & $4-8$ weeks & Intersticial pneumonitis \\
\hline Townsend M [16] & $5 \mathrm{mg} / \mathrm{day}$ & Six years & Three months & Constrictive pericarditis \\
\hline Guptha SH [17] & $4 \mathrm{mg} / \mathrm{day}$ & Four years & Four months & Pleural thickening \\
\hline Hashiguchi S [18] & $3 \mathrm{mg} /$ day & Six years & Three months & Pleural effusion \\
\hline
\end{tabular}

* Missing data.

antibiotics such as nitrofurantoin and the sclerotherapeutic agents sodium morrhuate and absolute alcohol $[1,2]$.

Cabergoline is an ergoline derivative with potent dopamine agonist properties. It was approved by the Food and Drug Administration (FDA) in 1997 and has been marketed in Spain since 2001 for the treatment of signs and symptoms associated with Parkinson's disease [3]. The incidence of pleuro-pulmonary damage due to cabergoline is estimated to be between 2 and $6 \%[1,4]$.

The mechanism via which ergoline derivatives produce fibrosis (either pleuropulmonary, retroperitoneal or cardiac) seems to be related to their serotoninergic effect, acting as 5HT2b receptor agonists [5]. This leads to the activation of cellular mitogenesis (fibroblasts) inducing fibrosis in the organ affected (for instance, the cardiac valve, the pleura and so on) $[5,6-10]$.

The clinical presentation of drug-induced pleural effusion varies from asymptomatic forms to acute pleuritis [1], dry cough, dyspnea and distal swelling [4]. Chest X-ray shows the presence of uni- or bilateral pleural effusion with or without pulmonary infiltrates [4]. The biochemical analysis of pleural effusion usually corresponds to an exudate of lymphocytes and/or eosinophils with low ADA [1, 4]. Our patient presented all these features. Cases of constrictive pericarditis [11] and cardiac valve regurgitation [3] have also been reported. The time between the initiation of treatment and appearance of symptoms ranges between 5 and 48 months (Table 2); in our case, the clinical symptoms appeared after 3 years of treatment

Withdrawal of the drug leads to an improvement - on occasions, resolution of the pleural effusion - though the fibrotic changes in the pleura and parenchyma may persist $[1,4]$. Treatment with systemic corticoids reduces the pleural thickening and the pulmonary interstitial involvement although not all the patients have been treated with oral corticosteroids (Table 2). Our patient improved with the withdrawal of the drug though oral corticoids were added (prednisolone at doses of $1 / 2 \mathrm{mg} / \mathrm{Kg}$ weight in decreasing doses over 4 months) but some pleural thickening and parenchimal fibrotic damage remained. Our case meets four of Karch and Lasagna's five criteria [6, 19]. The fifth criterion (reintroduction of the drug to test side effects) could not be confirmed. Since the side effect was already known, it was not considered ethical to reinitiate the drug treatment after the clinical improvement. In the case of a pleural effusion with a lymphocyte exudate, any drug being administered as treatment should be considered a possible cause before a more exhaustive study is carried out which may incur unnecessary economic cost and discomfort to the patient [1].

For all these reasons, we agree with the authors who recommend radiology and a pulmonary function study prior to the start of treatment with an ergoline derivative, and subsequent active monitoring of pleuropulmonary toxicity. We also recommend follow-up studies of this potential side effect after a minimum of 6-12 months of treatment.

\section{CONFLICT OF INTERESTS}

Dr. Christian Domingo reports receiving lecture fees from GSK, ASTRA-ZENECA, NOVARTIS, BOEHRINGER, MENARINI, BAYER, CHIESI. There are no conflicts of interest for the rest of the authors.

\section{ABBREVIATIONS}

\begin{tabular}{|c|c|c|}
\hline ADA & $=$ & Adenosine Deaminase \\
\hline $\mathrm{COHb}$ & $=$ & Carboxyhemoglobine \\
\hline Chest CT & $=$ & Chest Computed Tomography \\
\hline CRP & $=$ & C-Reactive Protein \\
\hline DLCO & $=$ & $\begin{array}{l}\text { Diffusing Lung capacity for carbon } \\
\text { monoxide }\end{array}$ \\
\hline ESR & $=$ & Erythrocyte Sedimentation Rate \\
\hline FEV1 & $=$ & Forced Espiratory Volum in the 1st minute \\
\hline $\mathrm{FVC}$ & $=$ & Forced Vital Capacity \\
\hline $\mathrm{KCO}$ & $=$ & Corrected DLCO \\
\hline $\mathrm{LDH}$ & $=$ & Lactate Dehydrogenase \\
\hline
\end{tabular}




$$
\begin{array}{ll}
\mathrm{PaO} 2 & =\text { Arterial oxygen tension } \\
\mathrm{PaCO} 2 & =\text { Arterial carbon dioxide tension } \\
\mathrm{PSA} & =\text { Prostate Specific Antigen } \\
\mathrm{RV} & =\text { Residual Volume } \\
\mathrm{TLC} & =\text { Total Lung Capacity }
\end{array}
$$

\section{REFERENCES}

[1] John HT, Sahn A. Steven. In: Richard A, Matthay MD, Eds. Clinics in Chest Medicine. Philadelphia: WB Saunders Co. 2004; 25: 141-153.

[2] Villavicencio C, Ramirez-Sarmiento A, Gayete A, Santiago G, Orozco-Levi M. Early pleuropulmonary toxicity associated with cabergoline, an antiparkinsonian drug. Arch Bronconeumol 2007; 43: 519-22.

[3] Comunicación sobre riesgos de medicamentos para profesionales sanitarios. Cabergolina y riesgo de valvulopatía cardiaca. Ministerio de Sanidad y Consumo. Ref: 2007/06. 20 April, 2007

[4] Comet R, Domingo C, Such JJ, Ribera G, Sans J, Marin A. Pleuropulmonary disease as a side-effect of treatment with bromocriptine. Respir Med 1998; 92: 1172-4.

[5] Roth BL. Drugs and valvular heart disease. N Engl J Med 2007; 356: 6-9.

[6] Karch FE, Lasagna L. Towards the operational identification of adverse drug reactions. Clin Pharmacol Ther 1997; 21: 247-54.

[7] Dhawan V, Medcalf P, Stegie F, et al. Retrospective evaluation of cardio-pulmonary fibrotic side effect in symptomatic patients from a group of 234 Parkinson's disease patients treated with cabergoline. J Neural Trans 2005; 112: 661-8.
[8] Kvernmo T, Härtter S, Burger E. A review of the receptor-binding and pharmacokinetic properties of dopamine agonists. Clin Ther 2006; 28: 1065-78.

[9] Danoff SK, Grasso ME, Terry PB, Flymm JA. Pleuropulmonary disease due to pergolide use for restless legs syndrome. Chest 2001; 120: 313-6.

[10] Butlletí de Farmacovigilància de Catalunya. Valvulopaties per pergolida i cabergolina. Gener-Febrer. Generalitat de Catalunya. Departament de Salut 2007; vol. 5(1).

[11] Ciubutaru V, Poinsignon Y, Brunet-Bourgin F, Mestassi M, Rosenbaum D. Severe pleuropericarditis induced by long-term bromocriptine therapy, report of a case and review of the literature. Rev Med Interne 2004; 25: 310-4.

[12] Bhatt MH. Pleuropulmonary disease associated with dopamine agonist therapy. Ann Neurol 1991; 30: 613-6.

[13] Frans E. Pleuropulmonary changes during treatment of Parkinsons's disease with a long-acting ergot derivate, cabergoline. Eur Respir J 1992; 5: 263-5.

[14] Ling LH. Constrictive pericarditis and pleuropulmonary disease to ergot dopamine agonist therapy (cabergoline) for Parkinson's disease. Mayo Clin Proc 1999; 74: 371-5.

[15] Frank W. Low dose cabergoline induced intersticial pneumonitis. Eur Respir J 1999; 14: 968-70.

[16] Townsend M. Constrictive pericarditis and pleuropulmonary fibrosis secondary to cabergoline treatment for Parkinson's disease. Heart 2004; 90: e47.

[17] Guptha SH. Pleural effusion and thickening due to cabergoline use in a patient with Parkinson's disease. Eur J Intern Med 2005; 16: 129-31.

[18] Shuji H. Cebergoline-induced pleural effusion in an elderly patient with Parkinson's disease. Neurol Med 2006; 64: 614-9.

[19] Domingo C, Roig J. Neglected respiratory toxicity caused by cancer therapy. Open Respir Med J 2007; 1: 1-6. 